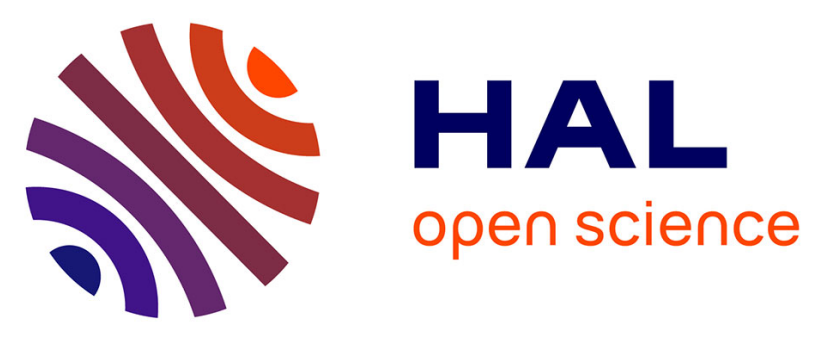

\title{
Involvement and alteration of the Sonic Hedgehog pathway is associated with decreased cholesterol level in trisomy 18 and SLO amniocytes.
}

Nicolas Gruchy, Nicolas Bigot, C. Jeanne Pasquier, Marie-Hélène Read, Sylvie Odent, Philippe Galera, Nathalie Leporrier

\section{To cite this version:}

Nicolas Gruchy, Nicolas Bigot, C. Jeanne Pasquier, Marie-Hélène Read, Sylvie Odent, et al.. Involvement and alteration of the Sonic Hedgehog pathway is associated with decreased cholesterol level in trisomy 18 and SLO amniocytes.. Molecular Genetics and Metabolism, 2014, 112 (2), pp.177-82. 10.1016/j.ymgme.2014.03.009 . hal-01021803

HAL Id: hal-01021803

https://hal-univ-rennes1.archives-ouvertes.fr/hal-01021803

Submitted on 26 Aug 2014

HAL is a multi-disciplinary open access archive for the deposit and dissemination of scientific research documents, whether they are published or not. The documents may come from teaching and research institutions in France or abroad, or from public or private research centers.
L'archive ouverte pluridisciplinaire HAL, est destinée au dépôt et à la diffusion de documents scientifiques de niveau recherche, publiés ou non, émanant des établissements d'enseignement et de recherche français ou étrangers, des laboratoires publics ou privés. 
Involvement and alteration of the Sonic Hedgehog pathway is associated with decreased cholesterol level in trisomy 18 and SLO amniocytes

Gruchy $\mathrm{N}^{1}$, Bigot $\mathrm{N}^{2}$, Jeanne Pasquier $\mathrm{C}^{3}$, Read $\mathrm{MH}^{4}$, Odent $\mathrm{S}^{5}$, Galera $\mathrm{P}^{2}$, Leporrier $\mathrm{N}^{1}$

1 Laboratoire de cytogénétique prénatale, service de Génétique, avenue Côte de Nacre, CHU Caen, UFR médecine 14033 Caen cedex 9, France

2 Laboratoire "Microenvironnement cellulaire et pathologie" (MILPAT) EA 4652, UFR Médecine Caen, avenue Côte de Nacre, 14033 Caen cedex 9, France

3 Service d'Anatomie pathologique, CHU Caen, UFR Médecine UFR médecine 14033 Caen cedex 9, France

4 Service de biochimie métabolique, CHU Caen, UFR Médecine UFR médecine 14033 Caen cedex 9, France

5 Génétique des pathologies liées au développement, CNRS UMR6290 UFR Médecine, Rennes, France

Corresponding author: Gruchy Nicolas : gruchy-n@chu-caen.fr Laboratoire de cytogénétique prénatale, service de Génétique, avenue Côte de Nacre, CHU Caen, UFR médecine 14033 Caen cedex 9, France. Telephone : +33231064008

Bigot Nicolas : nicolas.bigot@hotmail.fr

Jeanne Pasquier Corinne : jeannepasquier-c@chu-caen.fr

Read Marie-Hélène : read-mh@chu-caen.fr

Odent Sylvie : $\underline{\text { sylvie.odent @ chu-rennes.fr }}$

Galéra Philippe : philippe.galera@unicaen.fr

Leporrier Nathalie : leporrier-n@chu-caen.fr 
Involvement and alteration of the Sonic Hedgehog pathway is associated with decreased cholesterol level in trisomy 18 and SLO amniocytes

Gruchy $\mathrm{N}^{1}$, Bigot $\mathrm{N}^{2}$, Jeanne Pasquier $\mathrm{C}^{3}$, Read $\mathrm{MH}^{4}$, Odent $\mathrm{S}^{5}$, Galera $\mathrm{P}^{2}$, Leporrier $\mathrm{N}^{1}$

1 Laboratoire de cytogénétique prénatale, service de Génétique, CHU Caen, UFR médecine Caen, France

2 Laboratoire "Microenvironnement cellulaire et pathologie" (MILPAT) EA 4652, UFR Médecine Caen, France

3 Service d'Anatomie pathologique, CHU Caen, UFR Médecine Caen, France

4 Service de biochimie métabolique, CHU Caen, UFR Médecine Caen, France

5 Génétique des pathologies liées au développement, CNRS UMR6290 UFR Médecine, Rennes, France 


\section{Abstract}

\section{Background}

Trisomy 18 and Smith Lemli Opitz syndrome are two polymalformative conditions in which a cholesterol defect has been noted. When they occur prenatally, they are associated with a decreased maternal unconjugated estriol $\left(\mathrm{uE}_{3}\right)$ level. Cholesterol plays an essential role in the Sonic Hedgehog pathway, allowing Shh protein maturation leading to its maximal activity. Many malformations in these two syndromes occur in Shh dependent tissues. We thus sought to assess whether a cholesterol defect could affect the Shh pathway and explain some of the observed malformations.

\section{Materials and methods}

We selected 14 cases of trisomy 18 and 3 cases of SLO in which the maternal $\mathrm{uE}_{3}$ level was decreased and reported malformations were observed after fetopathological examination. We correlated the number of malformations with maternal $\mathrm{uE}_{3}$ level. We then carried out cholesterol concentrations in separate culture media consisting of trisomy 18, SLO and control amniocytes. Finally, we analyzed the Shh pathway by testing the gene expression of several Shh components: GLI transcription factors, BMP2, BMP4, TGFB1, COL1A1 and

\section{COL1A2.}

\section{Results and discussion}

There was an inverse correlation between phenotypic severity and maternal $\mathrm{uE}_{3}$ levels in SLO and trisomy 18. The cholesterol levels in the amniocyte culture media were correlated with maternal $\mathrm{uE}_{3}$ levels and were significantly lower in T18 and SLO amniocytes, reflecting cholesterol defects. There was an alteration in the Shh pathway since expression of several genes was decreased in T18 and SLO amniocytes. However, these cholesterol defects were not solely responsible for the altered Shh pathway and the malformations observed. 


\section{Introduction}

The Hedgehog (Hh) cell-cell signaling pathway is conserved in animals and has critical roles in embryonic development. Hedgehog proteins are secreted morphogens that are involved in many biological processes during embryonic development, and dysregulation of the pathway leads to several human diseases. It is expressed in many tissues, especially those of the brain and limbs. Hh signaling organizes pattern formation in the embryonic limbs, neural tube and other structures, and also functions postembryonically in homeostatic processes such as tissue maintenance and regeneration [1]. In the resting state of $\mathrm{Hh}$ signaling, the transcriptional output of the pathway is held back by the membrane protein Patched (Ptc), which inhibits the seven-spanner Smoothened (Smo). The Hh pathway is activated when the secreted protein $\mathrm{Hh}$ binds and inactivates Ptc, thus relieving the inhibition exerted on Smo, rendering it active. Active Smo signals to the cytoplasm, leading to activation of the zinc finger transcription factors, the Gli proteins (Gli1, 2 and 3) in vertebrates [2].

Gli1 and Gli2 act primarily as transcriptional activators, and Gli2 is the primary activator of Hh target genes in neural tube patterning [3]. Gli3 can act as either a transcriptional activator or, if proteolytically processed, as a transcriptional repressor that keeps target genes inactive in the absence of ligand. Hh activity promotes transcriptional activation of target genes in two ways: it promotes formation of Gli activators and it blocks the proteolytic processing event that creates the Gli3 repressor.

Shh is required for normal patterning of the limbs, where it regulates growth, digit number, and antero-posterior polarity [4].

Maturation of Hh protein needs the posttranslational addition of palmitate and cholesterol which both play a role in protein activity. Cholesterol level may be decreased in several 
instances. Its level has been reported to be low in at least two congenital defects: trisomy 18 and Smith-Lemli-Opitz syndrome [5,6].

Trisomy 18 is one of the most frequent aneuploidies found in 1/8 000 births. Presence of an extra chromosome 18 is responsible for a polymalformative syndrome in which facial anomalies such as microcephaly, dolichocephaly, cleft palate, congenital heart defects and limb anomalies may be found [7].

Smith-Lemli-Opitz syndrome (SLOS) is an autosomal recessive syndrome characterized by multiple congenital anomalies (craniofacial, limb), intellectual deficit and behavioral problems. SLOS is due to an inborn error of cholesterol synthesis and is caused by mutations in the DHCR7 gene (11q13.4) leading to a deficiency in the enzyme 3-beta-hydroxysteroldelta7 reductase that converts 7-dehydrocholesterol to cholesterol [8].

Both affections are characterized by an extremely low level of unconjugated estriol [3] measured in maternal serum during the $2^{\text {nd }}$ trimester of pregnancy, and it has been reported that individuals with either of these syndromes exhibit low cholesterolemia.

The aim of this study is to determine whether a cholesterol deficit may be responsible for phenotypic anomalies observed in these two syndromes that depend on the Shh pathway, i.e. craniofacial and limb anomalies. We studied cholesterol levels and the Shh pathway in 14 cultures of trisomic 18 amniocytes and 3 cultures of SLO amniocytes. 


\section{Materials and methods}

\section{Materials}

Among our cases of prenatal diagnoses, 12 cases of trisomy 18 and 3 cases of SLO were selected. Fetopathological examination was recorded for each case, and malformations were reported in Table I. The number of malformations was compared to maternal $\mathrm{uE}_{3}$ levels and 3 controls per trisomy 18 were chosen according to their term.

Amniocytes from these 60 cases were grown in RPMI® medium.

\section{Liquid chromatography associated with tandem mass spectrometry (LC/MSMS)}

There is only a tiny amount of cholesterol in the amniocyte culture medium, and the cholesterol originated by efflux from amniocytes is at very low level, so its dosage is impossible using biochemical or CPG/SM methods. It is only accessible using a more sensitive technique, liquid chromatography associated with tandem mass spectrometry (LC/MSMS) as a measurement technique LC/MSMS.

A range of cholesterol levels was established in the culture medium (RPMI®) (6 concentrations ranging from 0 to $50 \mu \mathrm{g} / \mathrm{mL}$ ) to perform a comparative quantitative dosage.

For each cell culture, the protein digests from both plasma and serum lipoprotein fractions were analyzed on an ion trap mass spectrometer interfaced with an autosampler through which samples were loaded onto a $\mathrm{C}_{18}$ capillary column $(100 \times 0.1 \mathrm{~mm})$. The capillary column was packed in-house with $5 \mu \mathrm{m} \mathrm{C}_{18} \mathrm{RP}$ particles (Phenomenex, Cheshire, UK). The solvents A and B, used for the chromatographic separation of peptides, were $5 \%$ acetonitrile in $0.1 \%$ formic acid and $95 \%$ acetonitrile in $0.1 \%$ formic acid, respectively. The protein 
digest, injected onto the microcapillary column, was separated at a rate of $150 \mu \mathrm{L} / \mathrm{min}$ in the following gradient conditions: 0-120 min 0-25\% B, 120-180 min 25-75\% B, 180-190 min 75$100 \% \mathrm{~B}, 190-200 \min 100 \% \mathrm{~B}, 215-300 \min 100 \% \mathrm{~A}$.

Quantification was obtained through comparison with epicoprostanol used as an internal standard.

\section{Cholesterol levels in culture flasks}

Cholesterol levels were related to the amount of protein contained in flasks, made possible using the Bradford protein assay. It was expressed in $\mu \mathrm{g} / \mathrm{mL} / \mathrm{g}$ of protein and was performed for the 60 cultures.

\section{RNA isolation and real-time RT-PCR analysis}

Total RNA from the amniocyte cultures was extracted using Trizol (Invitrogen by Fisher Bioblock Scientific, Illkirch, France). After extraction, $1 \mu \mathrm{g}$ of DNase-I-treated RNA was reverse transcribed into cDNA in the presence of oligodT and Moloney murine leukemia virus reverse transcriptase (Invitrogen). The reaction was carried out at $37^{\circ} \mathrm{C}$ for $1 \mathrm{~h}$ followed by a further 10 -min step at $95^{\circ} \mathrm{C}$. Amplification of the generated cDNA was performed by realtime PCR in an Applied Biosystems SDS7000 apparatus with appropriate primers designed using Primer Express software. The relative mRNA level was calculated with the $2^{-\Delta \Delta C T}$ method.

The following Shh pathway gene expressions were analyzed with this method: transcription factors GLI1, GLI2 and GLI3, and target genes expressed in facial and skeletal bone 
formation $B M P 2, B M P 4, T G F \beta 1$ and collagen type I genes COL1A1 and COL1A2. Their expression was compared to GAPDH expression.

\section{Western blot analysis}

In order to confirm Shh pathway alteration, we performed Western blot analysis in trisomy 18 amniocytes compared to control amniocytes for Shh proteins BMP2 and COL1A1. They were all compared with GAPDH expression.

\section{Treatment of control amniocytes with HMG-CoA reductase inhibitor}

Control amniocytes were treated with an inhibitor of HMG-CoA reductase (atorvastatin ${ }^{\circledR}$ ) in order to deplete cholesterol levels in the amniocyte culture medium to the same level observed in trisomy 18 and SLO.

Treatment was performed with $50 \mu \mathrm{L}$ of $100 \mu \mathrm{M}$ atorvastatin ${ }^{\circledR}$. Culture medium was collected on day 1, day 2 and day 3 after treatment. This allowed us to obtain a cholesterol level as low as that observed in the culture medium of trisomy 18 amniocytes.

\section{Results}

Inverse correlation between maternal $\mathrm{uE}_{3}$ levels and phenotypic severity in fetuses with

\section{SLO or trisomy 18.}

We observed that decreased maternal $\mathrm{uE}_{3}$ level was associated with a higher number of malformations observed in 12 fetuses exhibiting trisomy 18 and 3 fetuses with SLO. The 
mean number of malformations was significantly $(p=0.02)$ higher $(5.1)$ when $\mathrm{uE}_{3}$ was below 0.35 MoM than when it was higher (3.1 malformations).

Facial/cerebral anomalies were more frequent when $\mathrm{uE}_{3}$ was low. The association of cerebral/facial anomalies with limb anomalies was present in 4 fetuses out of 6 (when maternal $\mathrm{uE}_{3}<0.35 \mathrm{MoM}$ ) and 1 fetus out of 7 when maternal $\mathrm{uE3}>0.35 \mathrm{MoM}$ (Figure 1 ). The lower maternal $\mathrm{uE}_{3}$ is most frequently associated with facial and limb anomalies.

\section{Cholesterol concentration can be measured in culture medium and correlated with} maternal $\mathbf{u E}_{3}$ levels

Cholesterol levels measured from LC/MSMS were related to the amount of protein present in culture flasks and the mean cholesterol level in our culture flasks was approximately 10 $\mu \mathrm{g} / \mathrm{mL} / \mathrm{g}$ of protein. According to our dosages, we found that cholesterol level out of protein ratio did not vary throughout the pregnancy period (data not shown) and we showed a correlation between maternal $\mathrm{uE}_{3}$ levels and cholesterol levels in the culture medium containing either control cases or trisomic 18 or SLO amniocytes. Results showing this trend are reported in Figure 2.

\section{Cholesterol level is significantly decreased in trisomy 18 and SLO amniocytes compared to control amniocytes}

We analyzed the cholesterol level in relation to term of pregnancy and found no significant difference throughout pregnancy, indicating that this concentration is valid independent of pregnancy term. Mean cholesterol level for each group (SLO, trisomy 18 and control) is reported in Figure 3. We observed that cholesterol level in culture medium is significantly 
higher ( $p<0.05$ and $p<0.01$ respectively) in controls $(15.21 \mu \mathrm{g} / \mathrm{mL} / \mathrm{g})$ than in cases of trisomy $18(11.54 \mu \mathrm{g} / \mathrm{mL} / \mathrm{g})$ and SLO $(6.52 \mu \mathrm{g} / \mathrm{mL} / \mathrm{g})$.

\section{Sonic Hedgehog pathway is altered in trisomy 18 and SLO amniocytes}

We reported an alteration in the Shh pathway using 2 different approaches.

Comparative expression of different target genes in the Sonic Hedgehog pathway is shown in

Figure 4. We observed that all Gli transcription factors have decreased expression in trisomy 18 and SLO amniocytes compared to control amniocytes. Gli3 is specifically decreased in trisomy 18 amniocytes, whereas Gli1 is predominantly decreased in SLO amniocytes.

Target gene expression of the Sonic Hedgehog pathway is significantly decreased in trisomy 18 amniocytes compared to control amniocytes. Results are shown in Table II.

Western blot analysis

Western blot analysis in trisomy 18 amniocytes compared to control amniocytes for proteins Shh, BMP2 and COL1A1 confirmed decreased expression of these proteins in trisomy 18 amniocytes (Figure 5).

\section{Cholesterol defects alone, induced by treatment, does not alter Shh pathway as observed} in trisomy 18 and SLO

After treating control amniocytes with an inhibitor of cholesterol synthesis, we tested these cells for alterations in the Shh pathway by performing RT-PCR analysis of the previously tested genes. Tests showed a trend towards decreased expression of these genes in treated 
amniocytes, but it was not as low as that observed in trisomy 18 or SLO amniocytes (Figure $6)$.

\section{Discussion}

Maternal $\mathrm{uE}_{3}$ level is measured during the second trimester of pregnancy for trisomy 21 screening. It is not only decreased in this affection, but also when fetuses carry trisomy 18 [10] or Smith-Lemli-Opitz syndrome [9,11]. In our study, we observed an inverse correlation between maternal $\mathrm{uE}_{3}$ levels and phenotypic severity, with fetuses exhibiting SLO, as Kratz (1999) and Tint reported [12,13]. However, these findings also correlated with trisomy 18, as a low $\mathrm{uE}_{3}$ level was associated with fetuses exhibiting significantly more clinical findings after fetopathological examination. Therefore, phenotypic abnormalities seem to be more severe when the maternal $\mathrm{uE}_{3}$ level is below $0.35 \mathrm{MoM}$.

The $\mathrm{uE}_{3}$ level is known to reflect fetal cholesterol biosynthesis. The association between SLO phenotypic severity and cholesterolemia has already been reported where severity is correlated to 7-DHCR residual activity [12]. However, this has never been described in T18 pregnancies. It is well known that hypocholesterolemia is found in Smith-Lemli-Opitz syndrome due to an enzymatic defect in the cholesterol biosynthesis pathway (7-DHCR) [14]. Hypocholesterolemia is also present in rare cases of living trisomic 18 patients [11]. Unfortunately, no enzymatic defect has been reported in this aneuploidy, but 7-DHC level is low, indicating a possible block upstream. It would be of interest to establish a sterol profile in the case of trisomy 18 in order to determine a possible enzymatic block in cholesterol synthesis. In the different syndromes associated with an enzymatic defect in cholesterol biosynthesis, low cholesterol level alone is not sufficient to explain all the malformations 
observed. However, the possible toxic role of a precursor accumulation has been discussed $[15]$.

Maternal apolipoprotein E (apoE) genotype also plays a role, as these apolipoproteins are involved in materno-fetal cholesterol transport [16], with maternal homozygous apoE2 associated with more severely affected fetuses. Indeed, cholesterol intake from the mother may lower phenotypic severity.

We analyzed the cholesterol level in an amniocyte culture medium, a study that has not yet been reported. It reflects the cellular cholesterol level released by efflux [17]. The amount of cholesterol is tiny, making it impossible to measure using automated biochemistry. We thus performed measurements using an assay technique with better sensitivity, i.e. LC/MSMS, allowing cholesterol detection at very low levels and unaffected by culture medium and color. We observed a disturbance in cholesterol biosynthesis in trisomic 18 amniocytes, which correlates with the $\mathrm{uE}_{3}$ level measured in maternal serum. This cholesterol level is lowered by $30 \%$ in the cases of trisomy 18 and $60 \%$ in the cases of SLO, reflecting the more severe hypocholesterolemia observed in the cases of SLO. This difference may originate from a supply from another enzymatic pathway or more efficient materno-fetal cholesterol transport. A significant decrease in cholesterol level in amniocyte culture medium is associated with low maternal $\mathrm{uE}_{3}$ and reflects a disturbance in the fetal cholesterol biosynthesis pathway.

The association of both cerebrofacial and limb abnormalities correlates to the maternal $\mathrm{uE}_{3}$ level. Moreover, we showed that limb abnormalities were constant among patients with $\mathrm{uE}_{3}<0.35 \mathrm{MoM}$. We thus may hypothesize that there is an impact of this cholesterol disturbance on these tissues. However, their embryogenesis depends highly on the Shh pathway which needs cholesterol for its maturation. Thus it is not surprising to observe these malformations as Shh expression is predominant in notochord, brain, ZPA and bowel [18]. 
The link between Hh signaling and cholesterol is well established, as posttranslational addition of cholesterol plays a fundamental role in Shh maturation, where it helps to define the maximal activity of this morphogen due to liposolubility. However, the mechanisms of signal disruption are still insufficiently understood and there are contradictions regarding the role of cholesterol in long range signaling, where cholesterol can play an essential role [19] or can be unnecessary $[20,21]$. We thus sought to assess the role of an altered Shh pathway in the pathogenicity of trisomy 18 and SLO, since many genes are Shh pathway targets, among them genes involved in brain and limb embryogenesis.

We demonstrated a decrease in all Gli transcription factor expression, as reported by Gofflot [22] in a SLO animal model treated with a DHCR7 inhibitor, AY-9944, which showed a significant decrease in Shh pathway target genes. Similarly, we reported a significant decrease in $B M P 2$ expression, underlining a direct link between Shh and BMP2, but without a significant decrease in BMP4 expression, which is preferentially involved in dorso-ventral limb patterning and not directly linked to Shh [23]. Gofflot et al. also described an imbalance in Ihh expression in the forming cartilage of a rat model treated with triparanol, an inhibitor of the 24-dehydrocholesterol reductase, leading to syndactyly, with $B m p 2$ participating to the programmed cell death in digit formation [24]. We also reported a decreased expression of more downstream genes, such as type 1 collagen. This was expected since this collagen type is a target of BMP2 and TGF $\beta 1$. Type 1 collagen is a fibril-forming collagen found in most connective tissues which is abundant in bone, cornea, dermis and tendon. Its role in embryogenesis is predominant in bone formation and palatal fusion [25], and we may hypothesize that an alteration in its expression may participate to the occurrence of cleft palate which exists in our 3 SLO cases and 2 out of our 14 T18 cases. TGF $\beta 1$ expression, an important proliferation factor, was also decreased, which may in part explain in utero growth 
retardation, present in our 3 SLO cases and 4 out of our 14 T18 cases. In addition, limb shortness seems to be associated with deficiency in cholesterol biosynthesis during embryonic development.

We tested whether this pathway alteration was associated with cholesterol deficit by treating normal amniocytes with an inhibitor of cholesterol synthesis (Atorvastatin) and testing gene expression of previously altered genes. Treatment led to a decrease of the same magnitude as that observed in trisomy 18 and SLO. However, despite a trend towards decreased expression, it was not significant. We may hypothesize that this lack of treatment impact may either be due to a weak sensitivity of amniocytes to treatment, or insufficient treatment time, or a supply of other sterols in this in vitro model, or a combination of these events. Therefore, the cholesterol level decrease attributable to the treatment is not solely responsible for altered expression of downstream genes in the pathway. There is the need for other disturbing events to alter the pathway, which is similar to what Cooper et al. reported in an in vitro model of fibroblastic NIH3T3 cells. Compactin alone, an inhibitor of the HMG-CoA reductase, does not alter the pathway, whereas the addition of cyclodextrin, a cyclic oligosaccharide that depletes cells in cholesterol and affects Smo conformation does. However, they showed that pathway activation at the level of Gli1 was not affected, which is concordant with an effect on signal response and not its biogenesis demonstrating that this response also needs to be explored [6].

Using a different approach, we confirmed Shh pathway alteration in trisomy 18 as part of a decrease in Shh proteins BMP2 and COL1 expression in trisomic 18 amniocytes compared to normal amniocytes. Protein data clearly highlight Shh pathway alteration at different levels in trisomy 18 amniocytes. However, clear data on SLO amniocytes are lacking and further experiments are needed to address this question. 
Finally, we demonstrated Shh pathway alteration in both trisomy 18 and SLO amniocytes using different approaches. This alteration may in part be due to a cholesterol defect, but other events are involved in this disturbance, and need to be explored.

\section{References}

[1] Kim J, Kato M, Beachy PA. Gli2 trafficking links Hedgehog-dependent activation of Smoothened in the primary cilium to transcriptional activation in the nucleus. Proc Natl Acad Sci U S A. 2009 Dec 22;106(51):21666-71

[2] Buttitta L, Mo R, Hui CC, Fan CM. Interplays of Gli2 and Gli3 and their requirement in mediating Shh-dependent sclerotome induction. Development. 2003 Dec;130(25):6233-43.

[3] Villavicencio EH, Walterhouse DO, Iannaccone PM. The sonic hedgehog-patched-gli pathway in human development and disease. Am J Hum Genet. 2000 Nov;67(5):1047-54.

[4] Tickle C. Making digit patterns in the vertebrate limb. Nat Rev Mol Cell Biol 2006 Jan;7(1):45-53

[5] Lam WW, Kirk J, Manning N, Reardon W, Kelley RI, Fitzpatrick D. Decreased cholesterol synthesis as a possible aetiological factor in malformations of trisomy 18. Eur $J$ Med Genet. 2006 Mar-Apr;49(2):195-9 
[6] Cooper MK, Wassif CA, Krakowiak PA, Taipale J, Gong R, Kelley RI, Porter FD, Beachy PA. A defective response to Hedgehog signaling in disorders of cholesterol biosynthesis. Nat Genet 2003 Apr;33(4):508-13.

[7] Cereda A, Carey JC. The trisomy 18 syndrome. Orphanet J Rare Dis. 2012 Oct 23;7:81. doi: 10.1186/1750-1172-7-81.

[8] Porter FD. Human malformation syndromes due to inborn errors of cholesterol synthesis. Curr Opin Pediatr. 2003 Dec;15(6):607-13.

[9] Schoen E, Norem C, O'Keefe J, Krieger R, Walton D, To TT. Maternal serum unconjugated estriol as a predictor for Smith-Lemli-Opitz syndrome and other fetal conditions. Obstet Gynecol, $2003 ; 102: 167-72$.

[10] Leporrier N, Herrou M, Herlicoviez M, Leymarie P. The usefulness of hCG and unconjugated oestriol in prenatal diagnosis of trisomy 18. Br J Obstet Gynaecol. 1996 Apr ;103(4) :335-8

[11] Shinawi M, Szabo S, Popek E, Wassif CE, Porter FD, Potocki L. Recognition of SmithLemli-Opitz syndrome (RSH) in the fetus : utility of ultrasonography and biochemical analysis in pregnancies with low maternal serum estriol. 2005 Am J Med Genet 138A:56-60.

[12] Kratz LE, Kelley RI. Prenatal diagnosis of the RSH/Smith-Lemli-Opitz syndrome. Am J Med Genet. 1999 Feb 19;82(5):376-81. 
[13] Tint GS, Salen G, Batta AK, Shefer S, Irons M, Elias E, Abuelo DN, Johnson VP, Lambert M, Lutz R, Schanen C, Morris CA, Hoganson G, Hughes-Benzie R. Severity and outcome correlate with plasma sterol levels in type I and type II variants of the Smith-LemliOpitz syndrome. J Pediatr 1995127 : 82-87.

[14] Kelley RI, Hennekam RC. The Smith-Lemli-Opitz syndrome. J Med Genet. 2000 May;37(5):321-35.

[15] Gaoua W, Wolf C, Chevy F, Ilien F, Roux C. Cholesterol deficit but not accumulation of aberrant sterols is the major cause of the teratogenic activity in the Smith-Lemli-Opitz syndrome animal model. J Lipid Res. 2000 Apr;41(4):637-46.

[16] Witsch-Baumgartner M, Gruber M, Kraft HG, Rossi M, Clayton P, Giros M, Haas D, Kelley RI, Krajewska-Walasek M, Utermann G. Maternal apo E genotype is a modifier of the Smith-lemli-Opitz syndrome. J Med Genet. 2004 Aug;41(8):577-84.

[17] Bidet M, Joubert O, Lacombe B, Ciantar M, Nehmé R, Mollat P, Brétillon L, Faure H, Bittman R, Ruat M, Mus-Veteau I. The Hedgehog receptor Patched is involved in cholesterol transport. PLoS One. 2011;6(9):e23834

[18] Odent S, Attié-Bitach T, Blayau M, Mathieu M, Augé J, Delezoïde AL, Le Gall JY, Le Marec B, Munnich A, David V, Vekemans M. Expression of the Sonic Hedgehog (Shh) gene during early human development and phenotypic expression of new mutations causing holoprosencephaly. Hum Mol Genet. 1999 Sep;8(9):1683-9. 
[19] Gallet A, Ruel L, Staccini-Lavenant L, Therond P. Cholesterol modification is necessary for controlled planar long-range activity of Hedgehog in Drosophila epithelia. Development $2006133: 407-418$.

[20] Callejo A, Torroja C, Quijada L, Guerrero I. Hedgehog lipid modifications are required for Hedgehog stabilization in the extracellular matrix. Development 2006 Feb;133(3):471-83.

[21] Dawber RJ, Hebbes S, Herpers B, Docquier F, van den Heuvel M. Differential range and activity of various forms of the Hedgehog protein. BMC Dev Biol. 2005 Sep 30;5:21.

[22] Gofflot F, Gaoua W, Bourguignon L, Roux C, Picard JJ. Expression of Sonic Hedgehog downstream genes is modified in rat embryos exposed in utero to a distal inhibitor of cholesterol biosynthesis Dev Dyn 2001 220:99-111.

[23] Bakrania P, Efthymiou M, Klein JC, Salt A, Bunyan DJ, Wyatt A, Ponting CP, Martin A, Williams S, Lindley V, Gilmore J, Restori M, Robson AG, Neveu MM, Holder GE, Collin JR, Robinson DO, Farndon P, Johansen-Berg H, Gerrelli D, Ragge NK. Mutations in BMP4 cause eye, brain, and digit developmental anomalies: overlap between the BMP4 and Hedgehog signaling pathways. Am J Hum Genet. 2008 82:304-319.

[24] Gofflot F, Hars C, Ilien F, Chevy F, Wolf C, Picard JJ, Roux C. Molecular mechanisms underlying limb anomalies associated with cholesterol deficiency during gestation : implications of Hedgehog signalling. Hum Mol Genet. 2003 May 15;12(10):1187-98.

[25] Pungchanchaikul P, Bloch-Zupan A, Ferretti P. Delayed osteoprogenitor differentiation in cleft-palate models. Cells Tissues Organs. 2010;192(5):283-91. 
Table 1.

Number of malformations observed in 12 cases of trisomy 18 (white) and 3 cases of SLO (gray) after fetopathological examination.

NTD: neural tube defect, CHD: congenital heart defect, VSD: ventricular septal defect, malf: malformations MoM: multiple of median.

\begin{tabular}{|c|c|c|c|c|c|c|c|c|c|c|c|c|c|c|c|c|}
\hline & & 1 & 2 & 3 & 4 & 5 & 6 & 7 & 8 & 9 & 10 & 11 & 12 & 13 & 14 & 15 \\
\hline & Maternal uE level (MoM) & 0.21 & 0.24 & 0.26 & 0.29 & 0.31 & 0.32 & 0.33 & 0.34 & 0.43 & 0.44 & 0.47 & 0.51 & 0.64 & 0.66 & 1 \\
\hline \multicolumn{17}{|l|}{ Malformations } \\
\hline Cerebral anomalies & & & & & & + & & & + & + & & + & & & & + \\
\hline Facial cleft & & & + & & + & & + & + & + & & & & & & & \\
\hline NTD & Spina bifida & & & & & + & & & & & & & & & & \\
\hline $\mathrm{CHD}$ & VSD & + & & + & + & & + & & + & + & & & + & & + & + \\
\hline Omphalocele & & + & & & & & & & + & & & & & & & \\
\hline Esophageal atresia & & + & & & & & & & & & & & & & + & \\
\hline Renal anomalies & & + & & + & + & & + & & & + & + & & + & & + & \\
\hline \multirow[t]{3}{*}{ Limb anomalies } & Syndactylies & & + & + & + & & + & + & & & & & & + & & \\
\hline & Hands & & & + & & + & & + & + & & & & & & & \\
\hline & Feet & + & & & & + & + & + & + & + & + & & + & + & + & \\
\hline Cystic hygroma & & & + & & & & & & & & + & & & & & \\
\hline Hypotrophy & & & + & + & + & & + & & & & & + & + & & + & \\
\hline Number of malf & & 5 & 4 & 5 & 5 & 4 & 6 & 4 & 6 & 4 & 3 & 2 & 4 & 2 & 5 & 2 \\
\hline
\end{tabular}




\begin{tabular}{|c|c|c|c|c|c|c|c|c|c|}
\hline & & \multicolumn{3}{|c|}{ Transcription factors } & TGFB1 & \multicolumn{4}{|c|}{ Morphogenesis genes } \\
\hline & SHH & GLI1 & GLI2 & GLI3 & TGFB1 & COL1A1 & COL1A2 & BMP2 & BMP4 \\
\hline $\mathrm{T} 18(10)$ & $=$ & $\downarrow \downarrow$ & $\downarrow$ & $\downarrow \downarrow \downarrow$ & $\downarrow \downarrow$ & $\downarrow$ & $\downarrow \downarrow$ & $\downarrow$ & $=$ \\
\hline SLO (3) & NA & $\downarrow \downarrow \downarrow$ & $\downarrow$ & $\downarrow$ & $\downarrow$ & $\downarrow \downarrow$ & $\downarrow$ & $\downarrow \downarrow$ & $\downarrow$ \\
\hline
\end{tabular}

Table II

Comparative expression of Gli transcription factors and Shh target genes in trisomy $18(n: 10)$ and SLO $(n: 3)$ cases compared to 8 control cases. NA : not available 


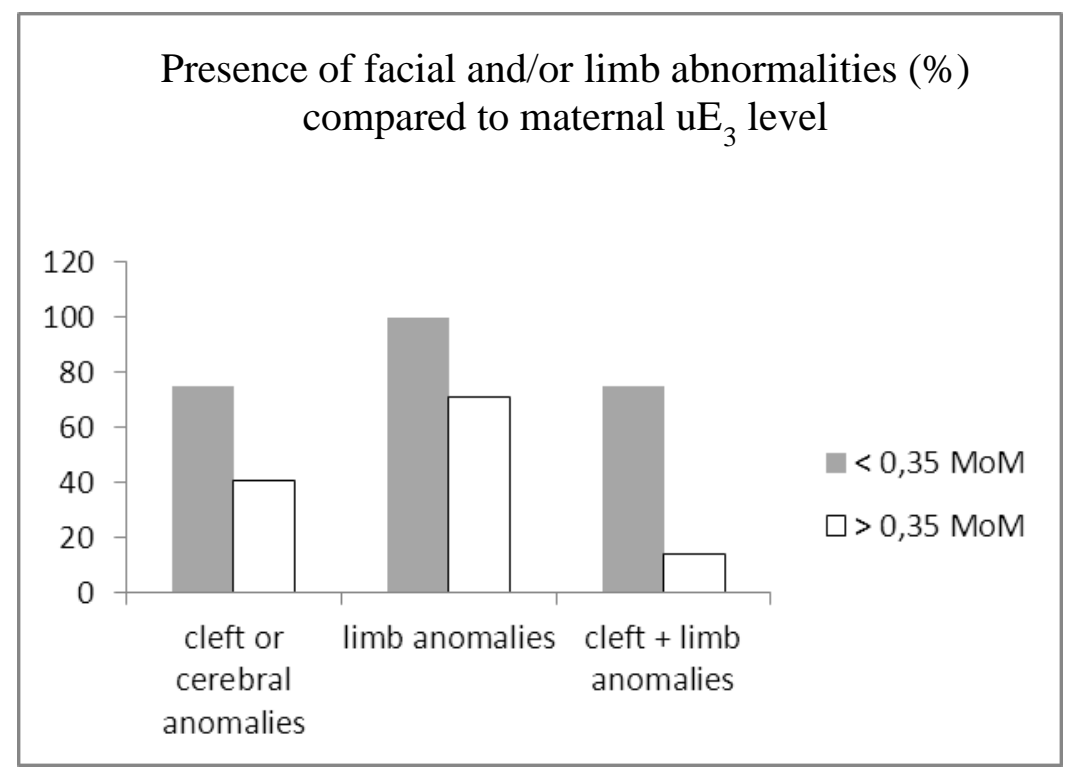

\section{Figure 1}

Facial and/or limb abnormalities were recorded in comparison to maternal $\mathrm{uE}_{3}$ levels $(<0.35 \mathrm{MoM}$ in grey, and $>0.35 \mathrm{MoM}$ in white). MoM : multiple of median. When maternal $\mathrm{uE}_{3}$ level is below $0.35 \mathrm{MoM}$, limb abnormalities are constant and the association of facial and limb abnormalities is much more predominant. 


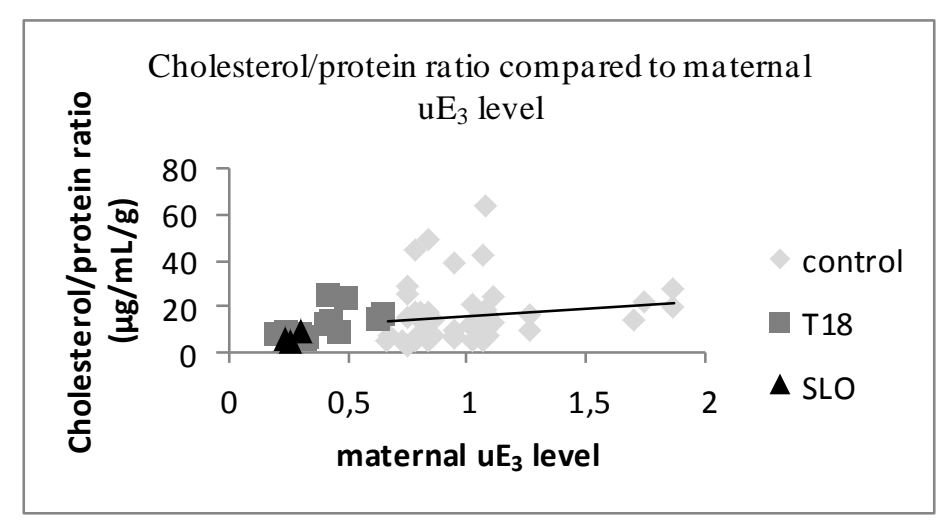

\section{Figure 2}

Cholesterol/protein ratios were compared to maternal $\mathrm{uE}_{3}$ levels measured during pregnancy in the 3 different groups analyzed (control, trisomy 18 and SLO cases). There is a correlation between cholesterol/protein ratios measured in amniocytes culture medium compared to maternal $\mathrm{uE}_{3}$ level. This trend is indicated through the black line (parametric Pearson's test, $\mathrm{p}<0.05$ ). 


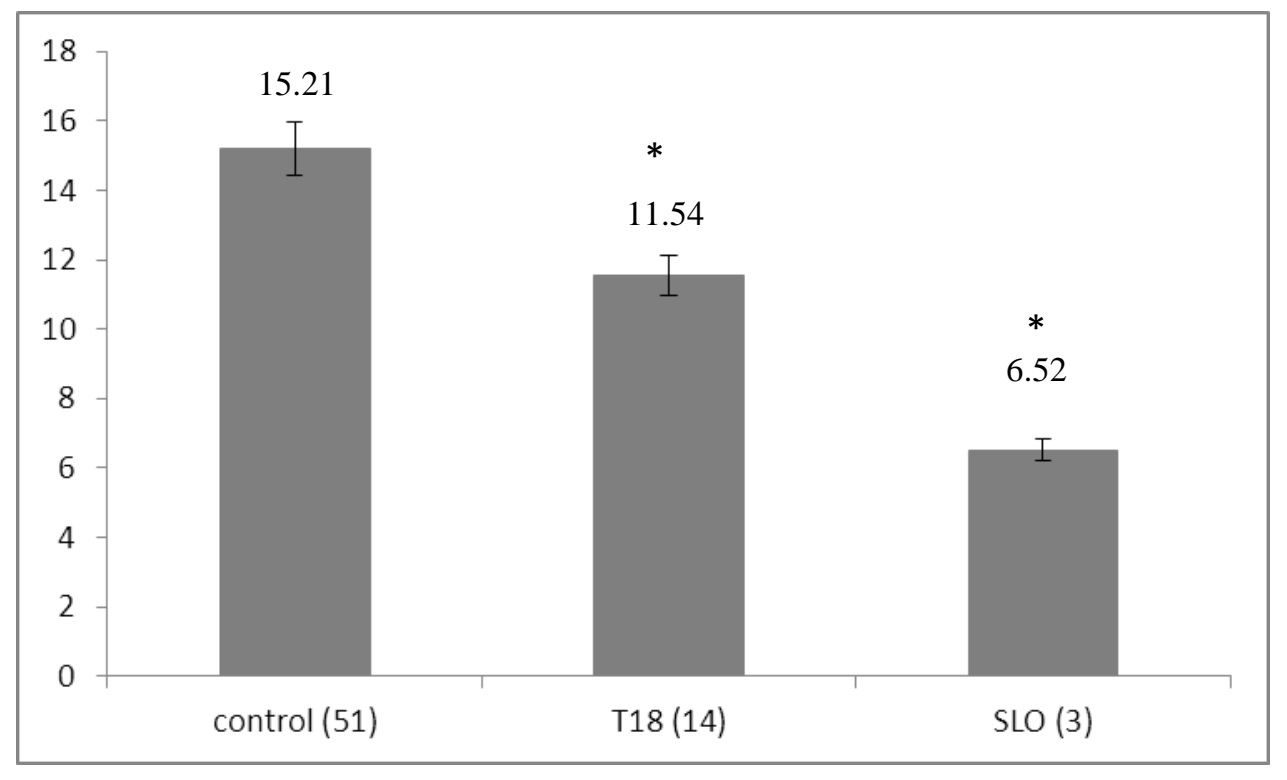

Figure 3

Cholesterol/protein ratios in the 3 different groups: control group ( $\mathrm{n}=45)$, trisomy 18 group $(\mathrm{n}=12)$ and $\mathrm{SLO}(\mathrm{n}=3)$. This ratio is expressed in $\mu \mathrm{g} / \mathrm{mL} / \mathrm{g}$ protein. It is significantly decreased in T18 and SLO groups, compared to control group. Statistical significance was evaluated using the Student's t-test $\left(^{*}: \mathrm{p}<0.05\right)$ 


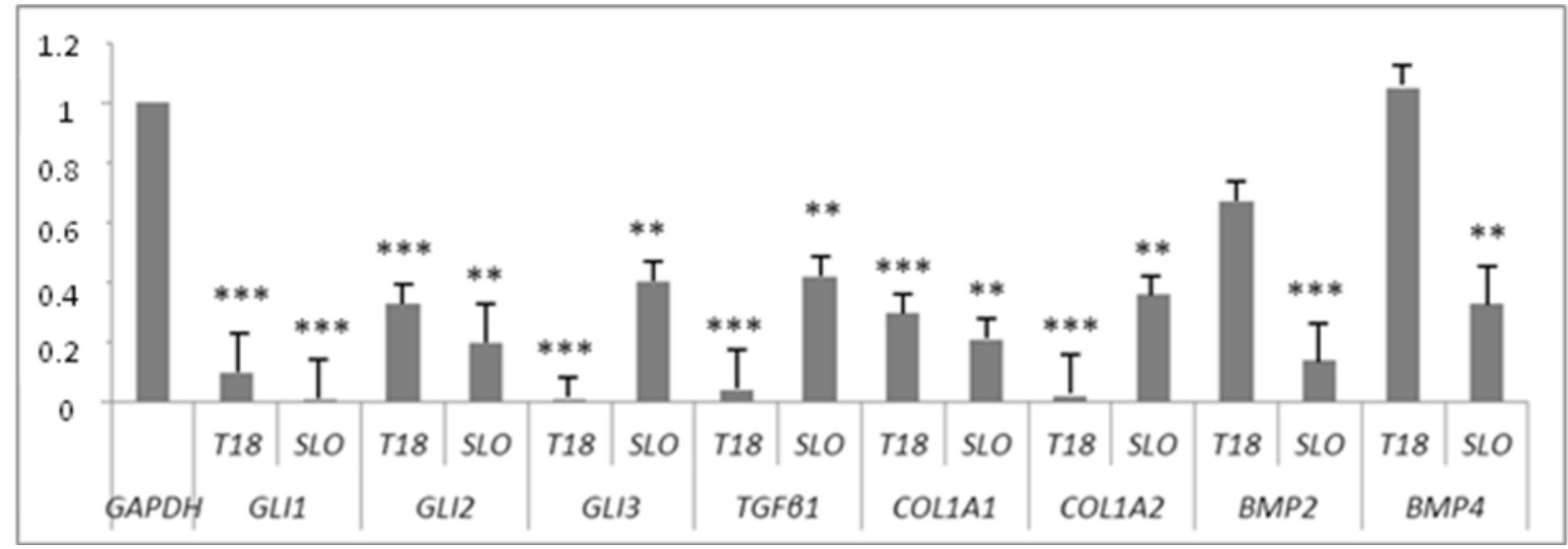

\section{Figure 4}

Comparative expression of different Shh pathway genes in T18 and SLO amniocytes, compared to control amniocytes. The expression is in arbitrary units with GAPDH as reference gene (1). Total RNAs were extracted from amniocytes and $1 \mu \mathrm{g}$ was reverse-transcribed into cDNA. The resulting products were diluted (1/100) and analyzed by real-time PCR using specific primers for GLI1, GLI2, GLI3, TGFB1, COLIA1, COL1A2, BMP2 and BMP4. Results were normalized to GAPDH cDNA. The expression shown is the average of 3 experiments. 8 control cases, 10 trisomy 18 cases and 3 SLO cases were analyzed. Statistical significance was evaluated using Student's t-test $(*: p<0.05 ; * *: p<0.01 ; * * *: p<0.001)$ 
A

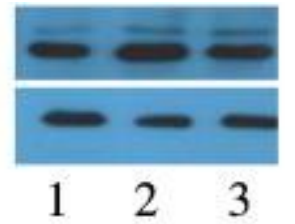

T18 Control Control

C

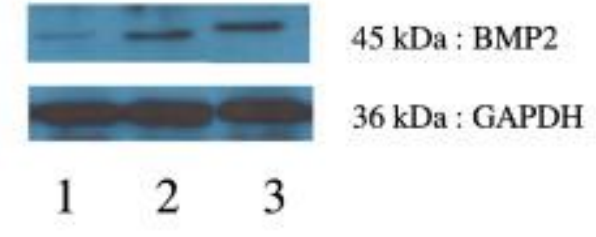

T18 Control Control
B

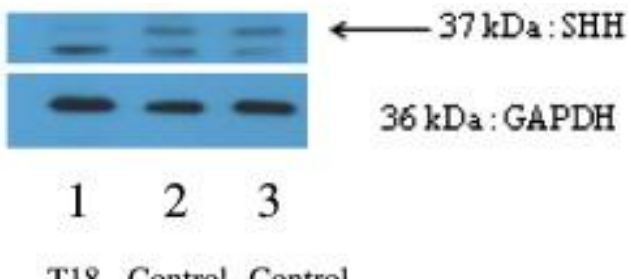

T18 Control Control

D

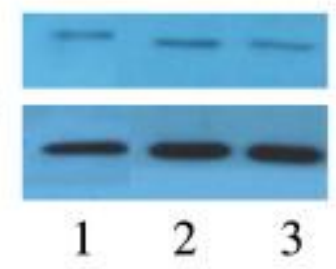

T18 Control Control

$45 \mathrm{kDa}$ : BMP2

$36 \mathrm{kDa}$ : GAPDH

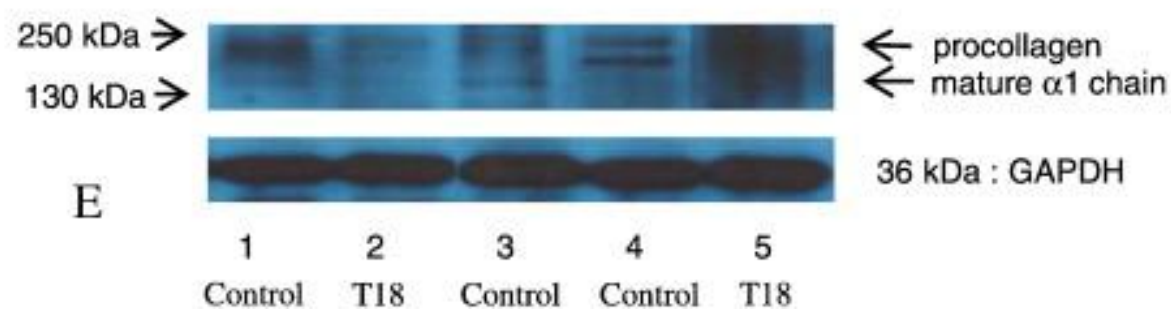

Fig. 5.

SHH, BMP2 and COL1A1 expressions are decreased in T18 amniocytes compared to control amniocytes.

$15 \mu \mathrm{g}$ of nuclear extracts from T18 or control amniocytes was separated on a 10\% polyacrylamide gel in denaturing conditions. Then, proteins were transferred to a PVDF membrane and immuno-blotted with polyclonal antibodies directed against SHH (A, B), BMP2 (C, D) and COL1A1 (E) and GAPDH as loading control. After washing with TBS-T, PVDF membranes were incubated with the appropriate secondary antibody and proteins were revealed with the super signal West-Pico® detection kit. 


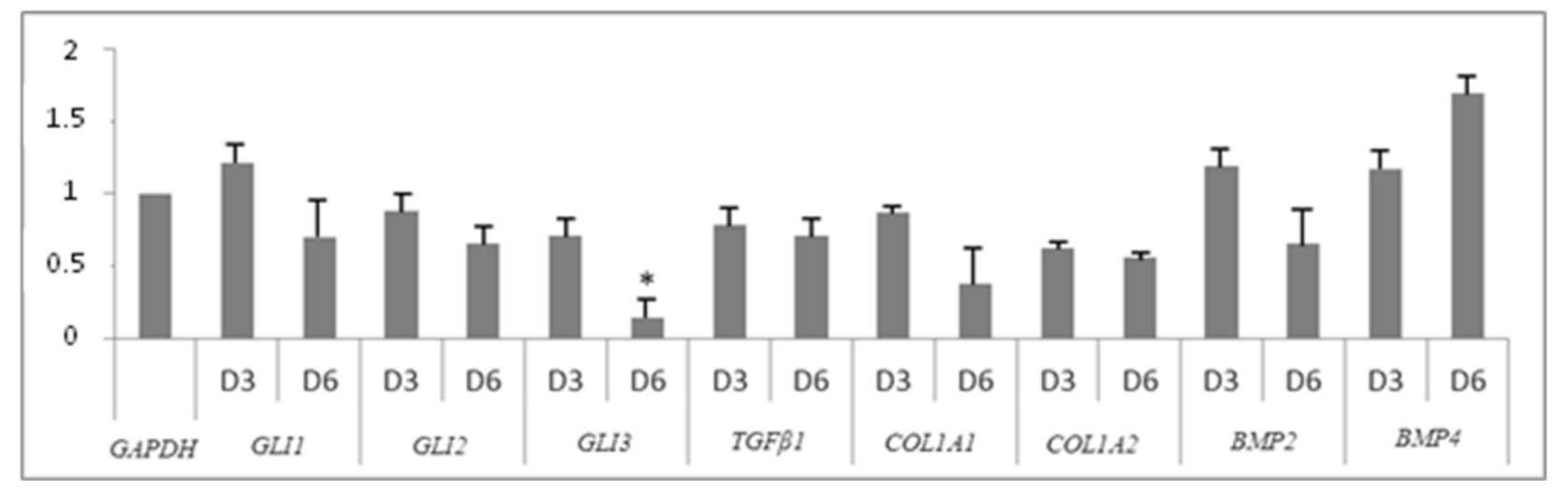

Figure 6

Comparative expression of different Shh pathway's genes in control amniocytes, after 3 (D3) or 6 days (D6) of treatment with an anti-cholesterol. The expression isin arbitrary unit with GAPDH as reference gene (1). Total RNAs were extracted from amniocytes and $1 \mu \mathrm{g}$ was reverse-transcribed into cDNA. The resulting products were diluted (1/100) and analyzed by real-time PCR using specific primers for GLI1, GLI2, GLI3, TGF 1 , COL1A1, COL1A2, BMP2 and BMP4. Results were normalized to GAPDH cDNA without treatment. The expression shown is the average of 3 experiments. We analyzed 3 cases at D3, and 5 cases at D6. Statistical significance was evaluated using the Student's t-test $(*: \mathrm{p}<0.05 ; * *: \mathrm{p}<0.01 ; * * *: \mathrm{p}<0.001)$ 